\title{
ミニコンピューターによる頭蓋内圧関連データの総合的表示
}

\author{
原圭太·中谷 進* ${ }^{*}$ 尾崎 孝次* ·池田 卓也**最上平太郎*
}

\section{Comprehensive Display of Intracranial Pressure-related Data with a New Minicomputer}

\author{
Keita Hara, Susumu NaKatani*, Kohji Ozaki*, Takuya IKeda** \\ and Heitaro MOGAMI*
}

Sharp Corporation Information Systems Group, Yamatokoriyama, Nara; ${ }^{*}$ Department of Neurosurgery, Osaka University, and ${ }^{* *}$ Central Operating Room Department, Osaka University Hospital, Osaka

\begin{abstract}
Measurement and analysis of intracranial pressure (ICP) are crucial to neurosurgery. It has been asserted that analogue data printouts of ICP do not provide enough information on the actual condition of the patient and make further data processing impossible. Most institutions, however, rely on this simple technique to classify patients, evaluate treatment effectiveness, and even to mathematically and statistically analyze the (possibly inaccurate and unreliable) data obtained. Although several microcomputer systems for ICP data processing have been developed recently, they handle only a fraction of ICP dynamics. The Data General DG 30 Minicomputer, a total system that includes comprehensive color graphic display and digital printing of ICP-related data, was developed with new techniques that improve algorithmic sampling and analysis. Included in the data display are vital signs, trend analysis and histographic array of mean ICP, mean blood pressure, and cerebral perfusion pressure, the ICP power spectrum of the B wave, intracranial compliance, and the A wave. This comprehensive presentation of ICP-related data provides a basis for more abjective evaluation of treatment modalities and may contribute substantially to studies of the value of ICP monitoring.
\end{abstract}

Key words: intracranial pressure, cerebral perfusion pressure, A wave, B wave, data processing

\section{I はじめに}

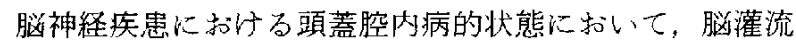
圧 (cerebral perfusion pressure: CPP)を至適レベルに保つた め, 頭蓋内生 (intracranial pressure: ICP) 测定の臨床的意 義は大きい.1960年, Lundberg多の持続的脳室圧モニタ一 についての最初の報告以来，持続的 ICP 測定の意義が認 識されるよらになった。しかし，チャートレコーダによる ICPのアナログデータ記録は必ずしも十分な情報を供給し ているとは言えず，また情報の二次的な処理曲不可能であ
るが，多くの場合，この不正確な方法により患者分類，治 療効果の判定, 統計的な分析が行われているのが現状であ る.最近，マイクロコンピューターを用いたICPデータ の処理に関する報告があるが，ICP 動態の一部分だけを扱 つたものが多い。我々はミニコンピューターを用いて ICP 関連データの量的表示を行い，一定期間内の ICP 克 進状態の客観的把握を陚み, 頭蓋腔コンプライアンスの表 示法を中心に, ICP 関連データのサンプリング法, データ 処理法, ディスプレイの力法について検討した。杰た，A 波，B 波の認識・娭出法について子検討したので，報告す 
$る$.

\section{II 処理万法および結果}

1. システム構成

システムの基本構成をFig. 1 亿示す。 日本Data General 社製 Desktop Generation Model 30 Minicomputer によりプログラム開発を行い，日本光電社製 Polygraph RM-6000, TEAG 社製 SR-30 Data Recorder を使用し, 脳

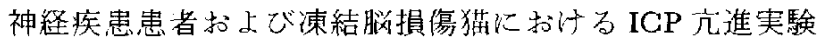
のデータを on-line · off-line 処理し， ハスク社製 GCX-4 Color Graphic Terminalに表示した。な招，血压(blood pressure: BP)は大腿動脈より腹部大動脈汇挿入したカテー テルを，ICPは脳室内カテーテルまたは硬膜下に㨉入した ウイッタカテーテルをそれでれ Statham-Gould 23Db Transducerに接続して測定した。

2.リアルタイムデータ処理法

生体信号をリフルタイム好理するには，データはコンピ ニーターに連続的に取り込去れていなけ狄な゙ならないるる のため，計測，時間計算，数值計算，プリントアウト，グ ラフィック表示などの複数の処理を並列に行らことができ るマルチタスクプログラム法を用いた。

\section{3. 頭蓋腔コンプライアンス表現法}

5 分間䧣でサンプリングタロック $100 \mathrm{msec} と し ， 10$ 秒間 (100個)のICPデータをとり，その標準偏差(standard

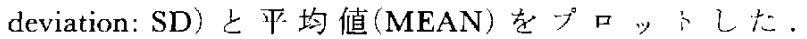

MEANがICPのレベルを表現し，SDが脈拍扰ざ呼吸 に同期する波の摇れ，つ主振幅を表し、コンプライアン ス哀表現するbの上仮定した。

4. $\mathrm{A}$ 波、 $\mathrm{B}$ 波の認識・検出法

Fig. 2 に，今回コンピーータ一解析に用いた典型的な

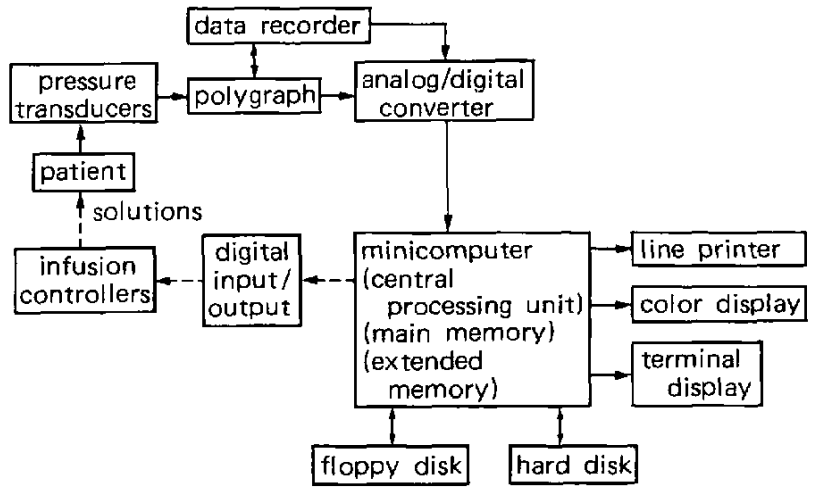

Fig. 1 Block diagram of the hardware configuration of the comprehensive display system of intracranial pressure (ICP) -related data.
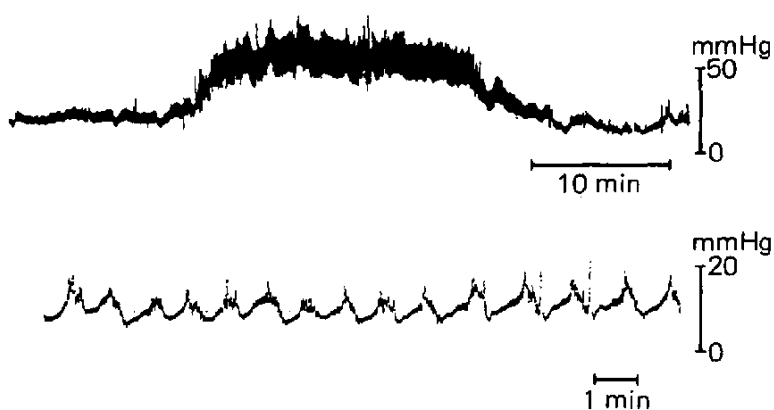

Fig. 2 upper: Polygraphic recording of a typical A wave of a patient with glioblastoma. The ICP plateau, which lasted for 20 minutes, was about $70 \mathrm{mmHg}$. lower: Polygraphic recording of a series of $B$ waves in a patient with hydrocephalus after subarachnoid hemorrhage. The base ICP was $10 \mathrm{mmHg}$, B waves with a peak of 20 mmHg appeared once per minute. Revised from Hara et al., Nippon Iryo Johogaku 7: 247, 1987.

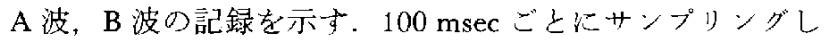
た 1 分間のサンプリングデータの面積平均法て計算された ICP の平均值が40 mmHg 越えると，A波である可能性 を認識する。艺の後， $40 \mathrm{mmHg}$ 以上の平均压が 5 分以上 続くと，A 波であると仮に認識寸る。この簡単な方法で, 一定時間内に 5 分以上続 $<40 \mathrm{mmHg}$ 以上のICP が何回出 現するかをチェックナることが可能である。

B 波の周期は 1 分間に1/2 2 回と呼吸执よび脈拍の周 期に比し遅く，その振幅は両者由来の振幅変動に比し大き い.一般以波形を分析するのに高速フーリエ変換7,12,15) (fast Fourier transform: FFT) の手法が用いられて招り， ICP 波形でる呼吸および脈拍由来成分とB波の成分をこ の才法で分離できる．FFTを行らにはサンプリングクロ

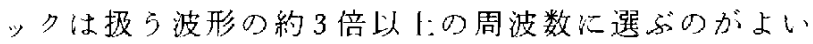
(Shannonの標本化定理 ${ }^{12,151}$ ) とされているため，30〜120 秒以 1 回のB波をターゲットにすると, サンプリングク 口ッタは 8 秒が適当である，Fig. 3 は，典型的な B 波を含 生 ICP 記録のパワースペクトルを表示したものである。 周期が約60秒の位置心0 dbを越光る大さな山がみられ， B波少椧出さ扎ている。

\section{ICP 関連データの総合的表示（Fig. 4, 5)}

$\mathrm{BP}, \mathrm{ICP}$ データを100 msec ごとにサンプリングし，1分 閻(600個)のデータから平均压, 収樎期压, 拡張期圧, CPPを上段左のトレンドダラフルプロットした。下段左 側には30分ごよの BP, ICP の平均府， CPP の度数分布を ヒストグラムフレイ表示し，また30分間のおのおのの度数 分布，最大値，最小值をプリントアウトした。さらに，上 段右に打いてICPパースペタトルを表示し，B波の検 


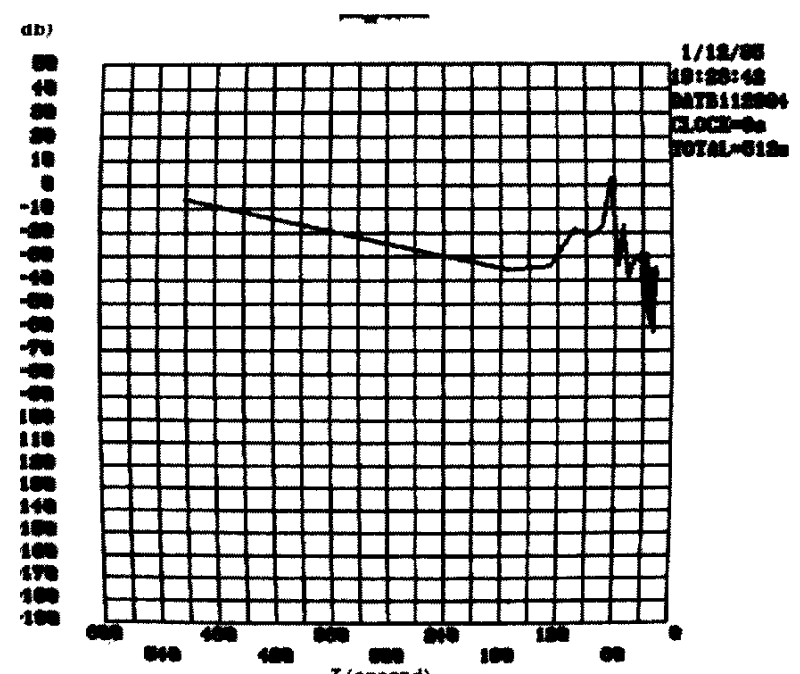

Fig. 3 Power spectrum of the ICP rccording, containing the serics of $B$ waves shown in Fig. 2. The ordinate shows the ICP power in $\mathrm{db}$, and the abscissa the time in seconds. A $0 \mathrm{db}$ peak is shown at 60 seconds, which corresponds to the $B$ wave frequency. Reprinted from Hara et al., Nippon Iryo Johogaku 7: 247, 1987.
出を行った．8分ごとに表示が変わり，同時に結果をプり ントアウトした。下段右端はSD-MEANプロットを示 し，頭蓋腔のコンプライアンスを表現し，SD拈よび MEANの值をプリントアウトした。

\section{(1) 脳神経疾患患者例}

Fig. 4 は，脳神経疾患患者のデータ表示例である，BP の変動之下降傾向に亦る ICP の長時間推移，その開 CPP が活とんど一选に保なれていることがヒストグラムアレイ により，上く表現されている。本た，ヒストグラムアレイ 表示を行えば，患者の体動斿どによるアーチフ、クトは統 計処理の過程で無視しらるるのとなることが判った。コン ブライアンス表现の SD-MEAN 直楾は，比較的勾配の小

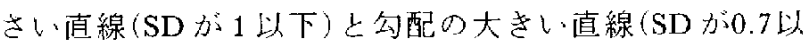
上)から成ることが認められた。ICPは止常域に集中して はいるものの，SD-MEAN 值線が比較的 ICP の低い地点 で站ち上がっていることは，コンプライアンスが小さいと

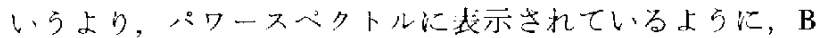
波が頻回炕出現しているためである之考えられる。

\section{（2）ネコにおける ICP 六進実験例}

Fig. 5 は，凍結脳損傷猫におけ引 ICP 几進实験のデー 夕㬵示例である。凍結脳損傷によりICPが徐々に上昇し
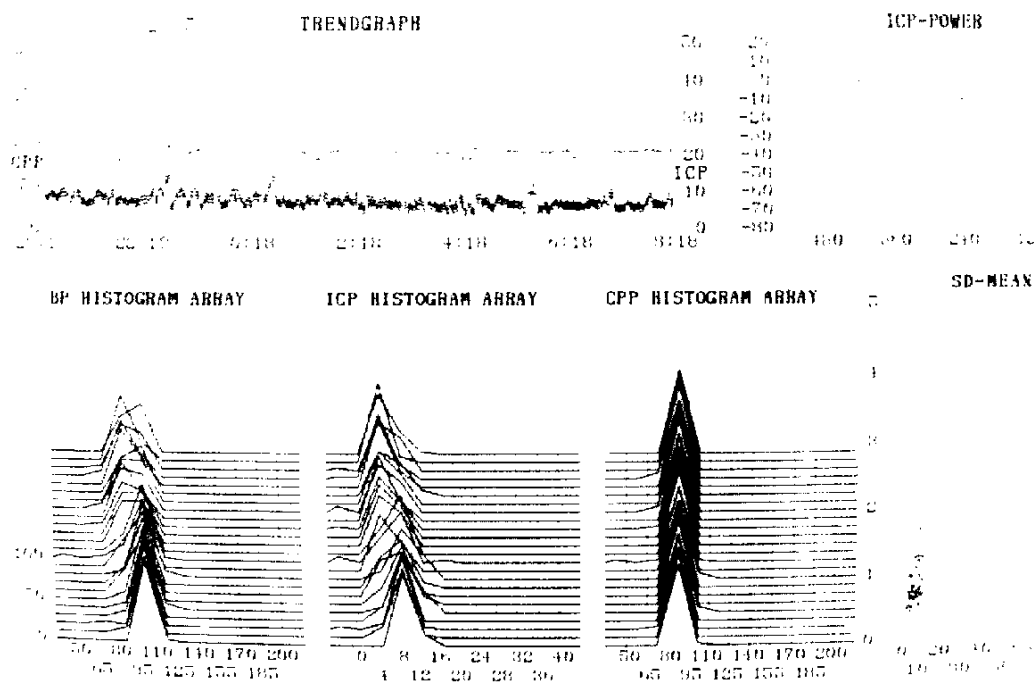

Fig. 4 A composite computer graphic display of ICP-related data of a neurosurgical patient. upper left: Trend graph of ICP, blood pressure (BP), and cerebral perfusion pressure (CPP). lower left: Percent frequency histographic array of ICP, BP, and CPP. up per right: ICP power spectrum showing B wave peaks, lower right: Standard deviation (SI)) and mean value (MEAN) of ICP. 


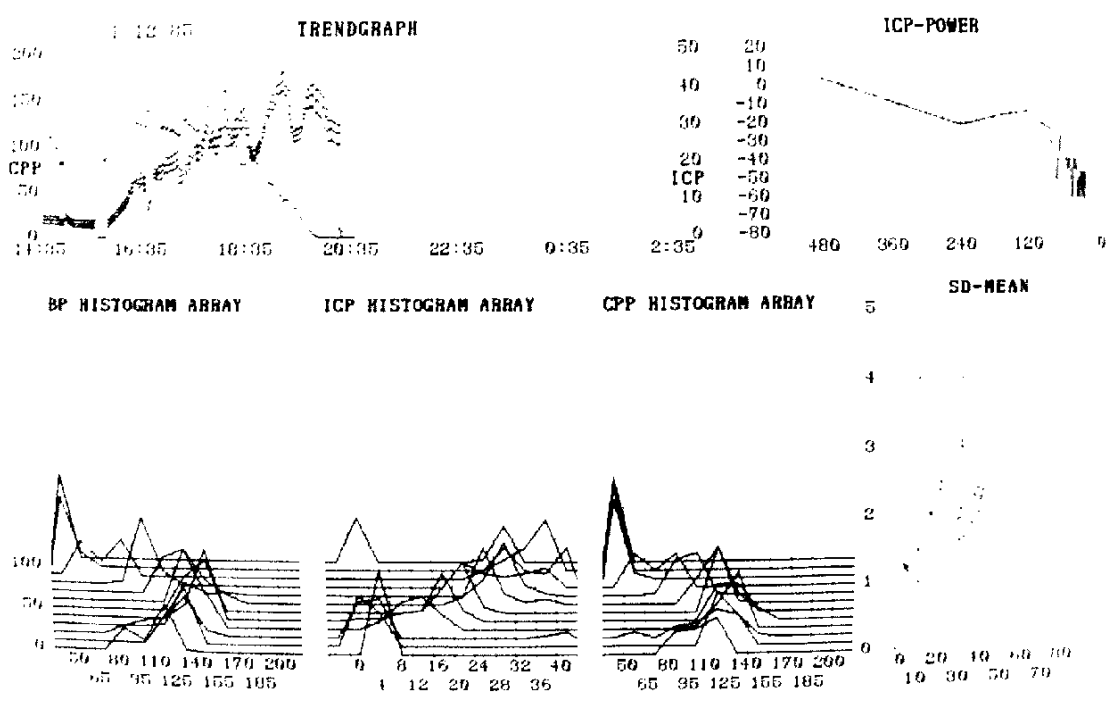

Fig. 5 A composite display of ICP-related data of a cat subjected to experimental IGP elevation. The divisions of the display are the same as those in Fig. 4.

ていること，ある時点までCPPがそれ汪ど大きく変化し ていないことなどがトレンドグラフ，ヒストグラムフレイ により，よく表現されている。実験開始 4 時間後, イソゾ ール注入によりこの例ではICPが返って上昇し，BPが 降下していることが判る。コンブライアンス表現の SD MEAN 目線は，SDの大きい部分でばらつきが大きいが， 公配の小さい直線(SD が1.3前後に集中) と勾配の人きい直 線〈SDが1.8以上)が認的れた。ハワースペクトル表示に おいてB波は挨出されていないのでこの二つの古線は 凍結脳損傷作製前之その後のICP 上昇時の状態をそれぞ れ表現していると考觉ら机る。

\section{III 考察}

ICP の释時的な变化を表現するため，一定時間サンブリ ングされたICPデータのヒストグラムを維軸方向にずら して描くヒストグラムアレイ法が用いら机る13!。我々はこ

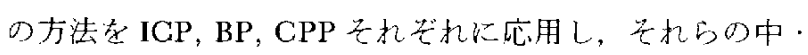
長期的絶対值の变動を攽易に捉学ることができた。李た， 度数分布に用いるデータとして単なるサンプリング值では なく面積平均值を用い，呼吸および脈拍に同期する波に上 る誤差を少なくした。しかし，ICP の絶対値の変動は頭蓋 内病的状態の重症度をある程度表現しているものの，頭蓋
腔コンプライアンスの汪らが ICP 環境を上り定期的に表 現すると指摘され1,2,9，最近ては ICP 波形の解析によるコ ンプライアンス表現が重視されるようになっている。

シンブライアンスが大きく，末だ代償作用がある状態で の頭蓋腔 $\mathrm{P}-\mathrm{V}$ 曲線は直線的である。も $\mathrm{P}-\mathrm{V}$ 曲線が直線 的であるとき，計算されるICP波の振幅はICPレベルに かか和らず一定である。一方，ェンプライアンスが小さ く, 代償作用が使い果された状態での頭蓋腔 $\mathrm{P}-\mathrm{V}$ 曲線は 指数関数的である.もし $\mathrm{P}-\mathrm{V}$ 曲線が指数関数的であると き, 計算される ICP 波の振幅と ICPレベルとの間には直 線関倸が牛じる5,10,111. したがって，心拍動に上って頭盖 内に送られてくる血液量 $\Delta \mathrm{V} か ゙$ 一定であるという条件卜 で流，打扰よそのところ，IGP波の振幅の増加はェラスタ ンスの增加，コンプライフンスの隇少を意味し，ICP振幅 の減少はエラスタンスの減少，コンプライアンスの増加を 意味寸ると考えられる，また，BPと ICPの波の伝澾とい らことから、コンブライフンスが小さい活ど BPが頭蓋内 に伝播する程度は高く，BP波の振幅がICP 波の振幅に反 映されや与くなり，コンプライフンスが大きいと 振幅がICP波の振幅に反映されにくいということにな $\succsim^{5,6)}$.

Szewczykowski ら ${ }^{10,11}$ は一定期閒の ICP サンプリング值 
のSDを計算し，その值により頭蓋腔コンプライアンスを 表現しよろとした，我々のシステムにおける頭蓋腔コンプ ライアンス表現法はこの考えに沿心なるのであるが，この 才法では体動などのアーチファクトが多い場合やB 波が 出現している場合には，ICP の脈拍に基つく振幅の大小を 示しているとは言えず，䛊差が生じやすい欠点があること が判明した，我々はFFT の手法を用い，ICP 波を脈拍拉 上び呼吸化同期する波，基礎压を表す波に分離し，分離し た波の振幅によりコンブライアンスを表現することを検討 している，また，ICP 元進には持続的な基礎レベルのえ進 のほか，Lundberg ${ }^{8}$ 汇より記載さ扎志典型的な型を示す短 期のICP 六進(圧波)が認められることがある、B 波が出 現しても比較的予後良好であるか，频回な $\mathrm{A}$ 波の出現は 予後不良を示唆するものであるから，この一つの压波を自 動的に認識し，量的に表示することは，頭蓋空コンブライ アンスの表示とともに，ICP 六進状態の客観的量的評価と して重要である。ICPが上昇しつつある過程に执いて，頭 蓋内病態が危険な状態に近付くことを予測し，適切な手段 を講ずるべきかどらかを判断するアルゴリズム開発の前段 階3,414)として不可欠であると考岳られる。

\section{$\mathbf{N}$ 結 語}

本システムによるICP関連データの総合的表示法によ ク，ICP 動熊の総合的，客観的な定量的評価が签易之なっ たが，さらに改良を加えることにより，頭蓋腔内・压環境 をより正確に捉えることができると思利机る。

\section{文献}

1) Chopp M, Portnoy HD: Systems analysis of intracranial pressure. Comparison with volume-pressure test and CSF-pulse amplitude analysis. I Neurosurg 53: 516-527, 1980

2) Chopp M, Portnoy HD, Branch C: Hydraulic model of the cerebrovascular bed. An aid to understanding the volumepressure test. Neurosurgery 13:5-11, 1983

3) Hagiwara I, Nakatani S: Automatic cerebral perfusion pressure control. A preliminary report, in Ishii S, Nagai H, Brock M (eds): Intracranial Ptessure V. Berlin, Springer, 1983, pp 163-166

4) Ikeda T, Nakatani S, Hagiwara I, Nakao K, Koshino K,
Mogami H: Prediction of ICP and pressure wave discrimination with our intelligent monitor system (IMNIC-1), in Ishii S, Nagai H, Brock M (eds) : Intracranial Pressure V. Bcrlin, Springer, 1983, pp $150-156$

5) 池山 㳯 : 頭盍腔内の $\mathrm{P}-\mathrm{V}$ relationship $と$ compliance $2 つ$ いて，後藤文男 (編)。頭蓋内压上脳浮腫. 東京, 中外製薬， 1983, pp 69-74

6) 池山淳, 前田 成, 永井 㢣 : 頭蓋内圧一容積圷と反映 圧一. 脳已神 28: 157-163, 1976

7) Lee YW : 第 2 章一般調和解析，第 7 章 時間平均上集合平 均. 宮川 洋, 今井秀樹(訳)。不規則信号論(上)。東京, 東 䒚大学出版会, 1981, pp 5-111, 229-246

8) Lundberg $\mathrm{N}$ : Continuous recording and control of ventricular fluid pressure in ncurosurgical practice, Acta Psychiatr Scand 36 [Suppl] 149: 1-193, 1960

9) Paltsev EL, Sirovsky EB: Intracranial physiology and biomechanics. J Neurosurg 57: 500-510, 1982

10) Szewczykowski J, Dytko P, Kunicki A, Korsak-Sliwka J, Sliwka S, Dziduszko J, Grochowski W, Augustyniak B: A method of estimating intracranial decompensation in man. J Neurosurg 45 : $155-158,1976$

11) Szewczykowski J, Sliwka S, Kunicki A, Dytko P, KorsakSliwka J: A fast method of estimating the elastance of the intracranial system. A practical application in neurosurgery. $J$ Neurosurg 47: 19-26, 1977

12）瀧保夫：信号波の解析と雑音，連続的情報の伝送. 電子 通信学会 (編)，通信方式. 東京, コロナ社:, 1981, pp 30-68, 111- 145

13) Tsutsumi $H$, Nishiyama $H$, Aruga $T$, Toyooka $H$, Mii $K$, Tsuzuki M, Manaka S, Takakura K: Usefulness of ICP histogram and ICP histogram array in ICP monitoring, in Ishii $\mathrm{S}$, Nagai H, Brock M (eds) : Intractanial Pressure V. Berlin, Springer, 1983, pp 135-139

14）堤 啨彦，豊岡秀訓，西山博実，有賀 徽，濱邊祐一，村 上泰, 三井香览, 都築正和, 高倉公朋: 頭蓋内丹自動 ニン トロール装置の試作。神経外傷 5: 147-154, 1983

15）臼井支郎，伊滕宏司，三田勝巳：第 2 章信号処理の基碟， 第4章 生体信号のスベタトル推定. 生体信号処理の基礎. 東 京, 才ーム社, 1985, pp 5-57, 107-165

[别刷請求先： $\mathbf{T} 639-11$ 宗良県大和郡山市美濃主町492, シャ一 プ懒報システム事業本部，原 主太」 